\title{
LiDAR DERIVED 3D CITY MODELLING
}

\author{
N. Polat ${ }^{1, *}$ \\ ${ }^{1}$ HRU, Engineering Faculty, 63200 Osmanbey Şanlıurfa, Turkey - nizarpolat@ harran.edu.tr
}

Commission VI, WG VI/4

KEY WORDS: LiDAR, Vaihingen, 3D City Model, Envi

ABSTRACT:

With the developing computer technologies and increasing data variety, academic and commercial studies started to move from 2 dimensions to 3 dimensions and within the concept of 3D Spatial Information Technology; Many new products and methods have emerged, such as the Digital Earth, Smart City, Virtual Reality, Intelligent Transportation Systems. 3D models of cities are now produced as well as 2D maps. These models can be used in many areas from urban planning, navigation applications, modelling of ancient cities to training and simulation applications. In this context, there are a few data set such as aerial images and LiDAR data, that can be used as 3D data source for modelling purposes. Within the scope of the study, an automatic 3D city model was produced with Envi LiDAR software.

\section{INTRODUCTION}

Maps have been and are still used by human beings for many centuries. Many types of maps are used, ranging from simple unscaled drawings to maps with different projections. Over time, new information has begun to be obtained from maps with the contribution of satellite images and geographical information systems. However, the rapidly developing technology and the widespread use of the internet have brought different needs and different products in this field. With the developing computer technologies and increasing data variety, academic and commercial studies started to move from 2 dimensions to 3 dimensions and within the concept of $3 \mathrm{D}$ Spatial Information Technology; Many new products and methods have emerged, such as the digital earth, smart cities, virtual reality, and intelligent transportation systems. 3D models of cities are now produced as well as 2D maps.

In fact, 3D city model production studies started in the nineties. States and private companies spend millions of dollars each year on this issue. These studies have been carried out in some cities such as Tokyo, New York and London, which are mostly over 1 million population and trade centres (Batty et al., 2000). Worldwide companies such as Google, Sony, Apple and Microsoft produce interactive 3D city models and share them with their users on the internet for free. Depending on the production accuracy of 3D city models, urban planning, environmental studies, city security, damage detection after natural disasters, search and rescue, entertainment-game industry, aviation studies and flight simulations, telecommunication network planning, tourism and even automatic use of new generation vehicles and It has become a basic requirement in many different applications such as mobile navigation. Brenner (2005) stated that 3D city models, which are easily accessible, provide location information, public and realistic, have become a very urgent need for many users, especially public institutions.
In 3D city models, the most basic elements of the city are buildings, roads, green areas, and water areas. Especially within the city structures, buildings are considered as basic objects and focus on building such as 3D building / city model production. In this context, it is necessary for many applications to produce 3D information about city structures and to make them available in the required data formats in digital environment. Today, studies conducted for this purpose use Photogrammetry, Remote Sensing, Computer Vision and computer-aided drawing technologies and software together. The European Organization on Spatial Data Research (EuroSDR) is making serious efforts in this regard: it provides free data, organizes training courses and academic meetings. Similarly, the International Society for Photogrammetry and Remote Sensing (ISPRS) sets up working groups on this subject, provides free data sets and announces the results of the work.

Apart from classical ground measurements, the first step of $3 \mathrm{D}$ city model production using remote sensing, photogrammetry and laser scanning is to determine the buildings to be modelled naturally by providing the highest automation and accuracy in the data set. The detection approach varies according to the data set used. Details of the preliminary work in this field can be found in (Baltsavias, 2004; Gruen et al., 1995; Kaartinen et al., 2005; Khoshelham et al., 2010; Mayer, 1999). The first studies were made mostly with image data. It mainly focuses on building detection from non-superimposed aerial photographs or satellite images (Shufelt and Mckeown, 1993; Zhang et al., 2006). Over time, overlapping aerial photographs have been used (Fradkin et al., 2001; Müller and Zaum ,2005). With the widespread use of digital surface models, height information has also taken place in these studies (Forlani et al., 2006).

Building detection studies started to shift from image data to point data with the production and widespread of laser scanning systems and especially the Light / Laser Detection and Ranging (LiDAR) system as a Remote Sensing system (Awrangjeb et al., 2013; Vu et al., 2009). Badenko (2019) suggested Envi LiDAR software due to its classification accuracy and fast operation,

\footnotetext{
* Corresponding author
} 
making a comprehensive comparison of commercial software. For this reason, in this study, a LiDAR data set provided by ISPRS and belonging to the city of Vaihingen in Germany was processed with Envi LiDAR and a 3D city model was produced. In this context, a city model was obtained using only the software's own library without using any reference data.

\section{METHODOLOJI AND DATA SET}

Vaihingen is a partly hilly and wooded city by the river. There are 3161825 points in the data set provided for this city. The average point density is 7.002 points $/ \mathrm{m}^{2}$ and the land height varies from $256.630 \mathrm{~m}$ to $293.140 \mathrm{~m}$. further information about data set can be found in Cramer scientific paper (2010).

Today, LiDAR (Light / Laser Detection and Ranging) is an active sensor technology that is used extensively for different purposes. This system provides the opportunity to obtain data very quickly and with high accuracy compared to conventional measurement methods. One of the biggest advantages is that the point cloud obtained is referenced in 3D. Laser scanning systems with active detection principle produce a laser light with high energy and narrow / thin physical dimension, send it to the target and record the returning light. The scanner records the travel and return time of each laser beam it sends and measures the distance between the objects struck by the sensor and the beam (Meng et al. 2010). Taking this measurement time into consideration, the current position of the platform is recorded by GPS and the current rotation of the plane with the IMU. All these recorded data are used to calculate the location of the measured object (Liu 2008). Within the scope of the study, 3D model of the region was produced by using Vaihingen LiDAR data and Envi LiDAR software. For this purpose, firstly, the classification of the point cloud is made. Thus, a healthier modelling is obtained by determining the points of buildings and other objects.

\section{APPLICATION}

At the beginning, the software creates a project name and folder. It then analyses the data set. Meanwhile, it analyses the limits of the data in three axes, if any, other auxiliary information such as scanning angle, intensity and returns (Figure 1), then brings the data set to the interface.

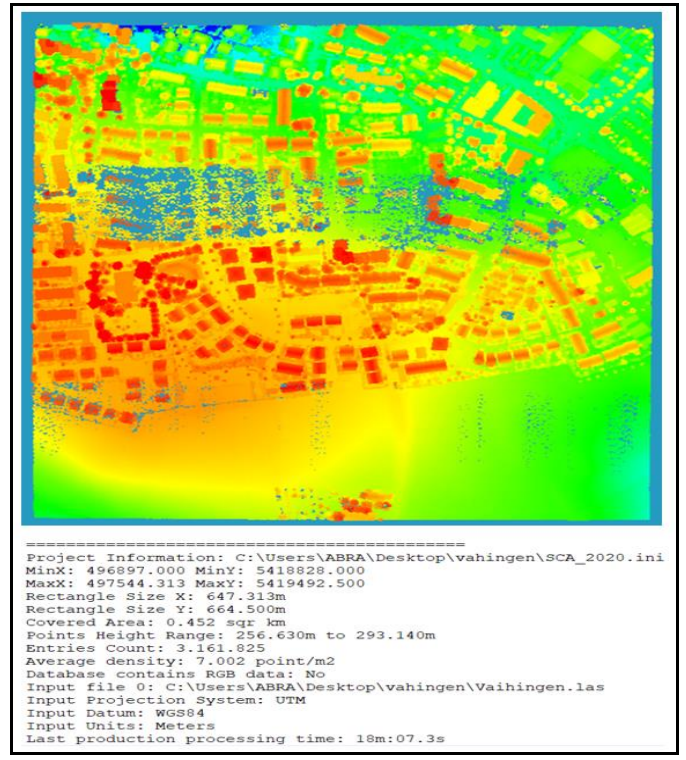

Figure 1. Data specifications and visualization
As stated above, firstly, the classification of the point cloud is made to obtain a healthier modelling. In this context, the data set is divided into land, trees, and buildings classes.

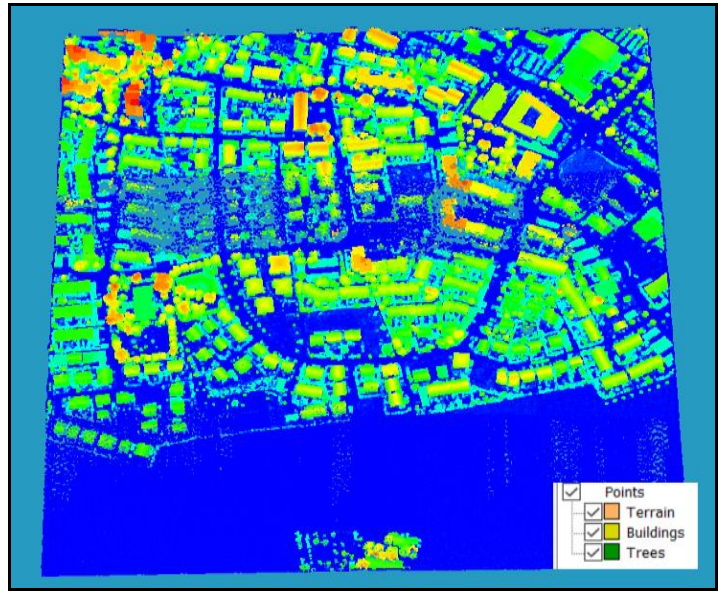

Figure 2. Classified LiDAR point cloud

Since the software classifies the points, DTM and DSM can also produce easily. It is also possible to export building boundaries as vector.

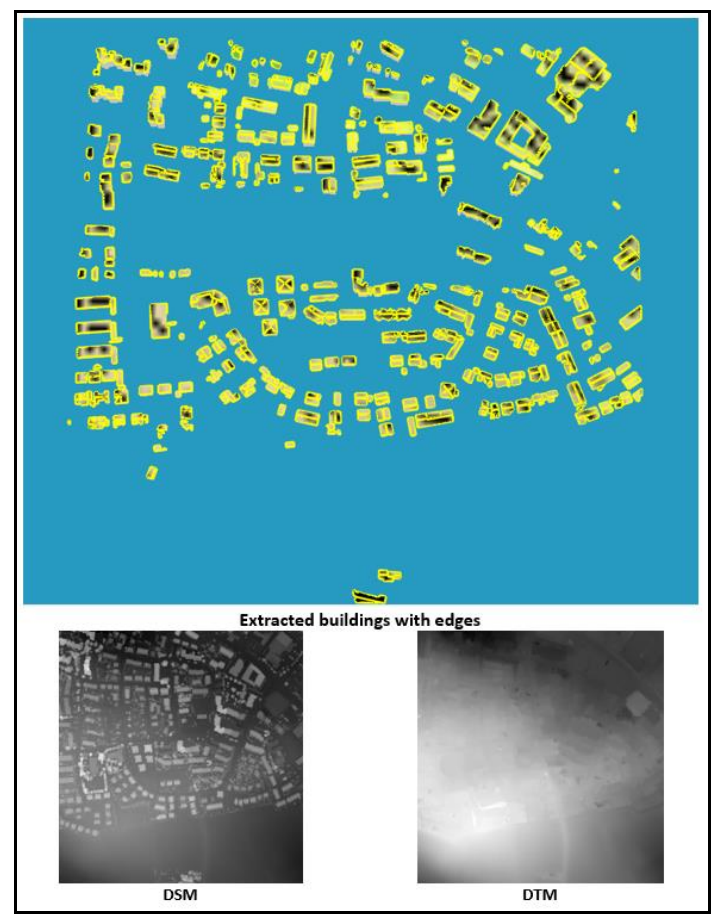

Figure 3. Extracted building boundaries and generated DSM and DTM

The software creates roofed and roofless buildings from its own library. The result is a city model that can be easily navigated and exported in Collada format. 


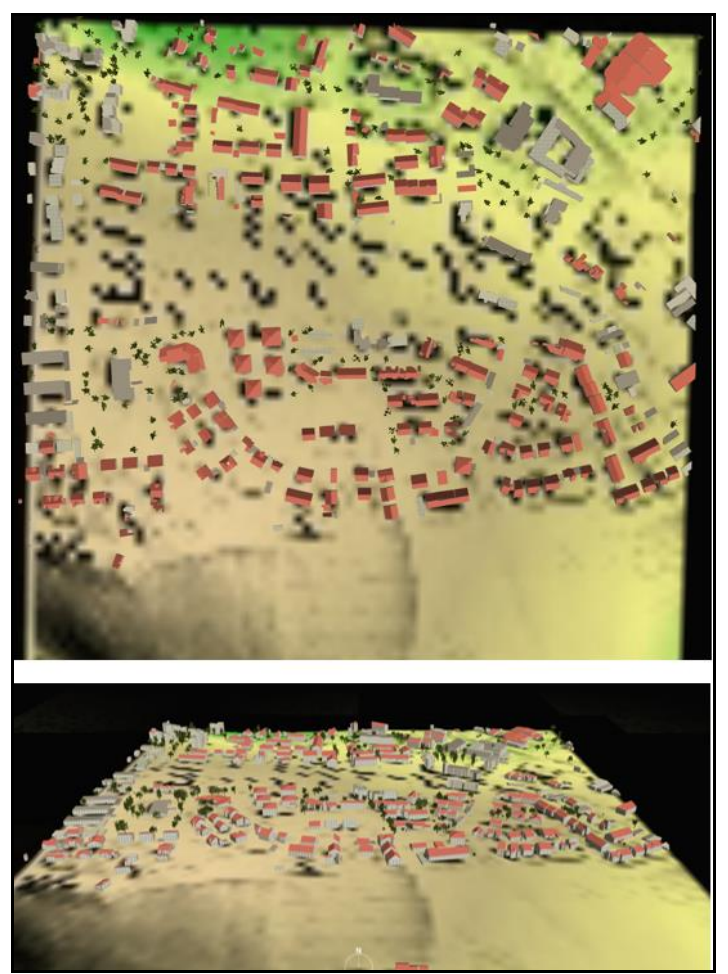

Figure 4. From top and side view of 3D models

A closer view of the models is given in Figure 5.

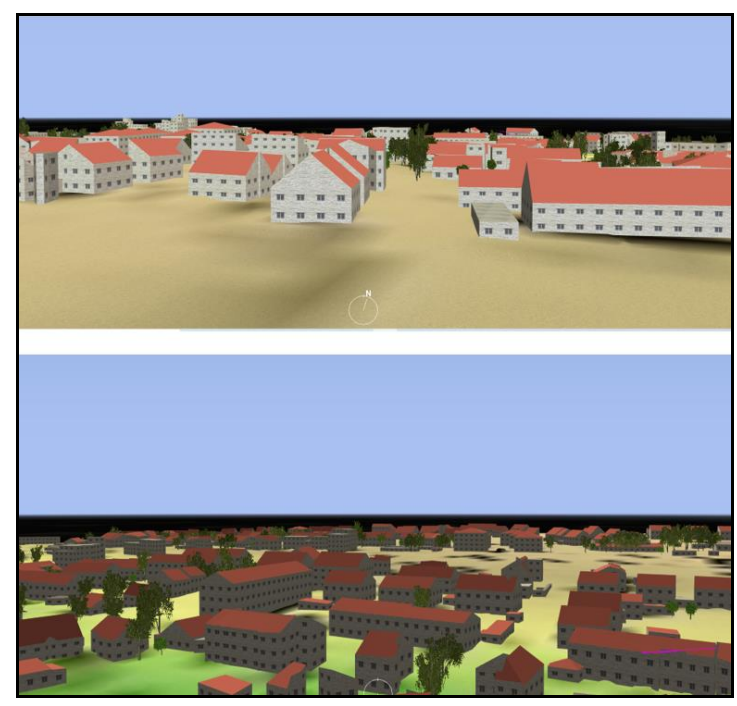

Figure 5. Closer view of the models

When the results are examined in detail, it is possible to say that the software has shortcomings. For example, although it determines the building points with great accuracy, there are serious mistakes in determining the boundaries. This situation is thought to be caused by trying to detect the roof. Similarly, the points belonging to the tree and tree groups are determined correctly, but there are errors in the point location. Nevertheless, thanks to the visuality and fast performance it provides, the $3 \mathrm{D}$ city model it produces can be used in many studies that do not require direct measurement.

\section{CONCLUSION}

Within the scope of this study, LiDAR data set belonging to Vaihingen was processed with Envi LiDAR software. In this context, point classes such as land, buildings and trees were created from the LiDAR data set. Later, DTM and DSM were produced. Finally, a 3D city model was produced using the building and roof models in the software's library. The software, which gives results in as little as 20 minutes in total, is remarkable thanks to its correct classification and fast operation.

\section{ACKNOWLEDGEMENTS}

The Vaihingen data set was provided by the German Society for Photogrammetry, Remote Sensing and Geoinformation (DGPF) [Cramer, 2010]: http://www.ifp.uni-stuttgart.de/dgpf/DKEPAllg.html.

\section{REFERENCES}

Chan, K.L., Qin K., 2017: Biomass burning related pollution and their contributions to the local air quality in Hong Kong. Int. Arch. Photogramm. Remote Sens. Spatial Inf. Sci., XLII2/W7, 29-36. doi.org/10.5194/isprs-archives-XLII-2-W7-292017.

Cramer, M., 2010. The DGPF test on digital aerial camera evaluation - overview and test design. Photogrammetrie Fernerkundung - Geoinformation 2(2010):73-82.

Batty, M., Chapman, D., Evans, S., Haklay, M., Kueppers, S., Shiode, N., ... Torrens, P. M, 2000: Visualizing the city: communicating urban design to planners and decision-makers. London Reports.

Brenner, C. 2005: Building reconstruction from images and laser scanning. International Journal of Applied Earth Observation and Geoinformation, 6(3-4): 187-198. https://doi.org/10.1016/J.JAG.2004.10.006

Baltsavias, E. P. 2004: Object extraction and revision by image analysis using existing geodata and knowledge: current status and steps towards operational systems. ISPRS Journal of Photogrammetry and Remote Sensing, 58(3-4): 129-151.

Gruen, A., Kuebler, O. Agouris, P. (Eds.). 1995: Automatic extraction of man-made objects from aerial and space images. Basel: Birkhäuser Basel. https://doi.org/10.1007/978-3-

Kaartinen, H., Hyyppä, J., Gülch, E., Vosselman, G., Hyyppä, H., Matikainen, L., ... Dragoja, M., 2005: Accuracy of 3D city models: EuroSDR comparison. In International Archives of the Photogrammetry, Remote Sensing and Spatial Information Sciences, "Laser scanning 2005"

Khoshelham, K., Nardinocchi, C., Frontoni, E., Mancini, A. and Zingaretti, P., 2010: Performance evaluation of automated approaches to building detection in multi-source aerial data. ISPRS Journal of Photogrammetry and Remote Sensing. https://doi.org/10.1016/j.isprsjprs.2009.09.005

Mayer, H., 1999: Automatic object extraction from aerial imagery - a survey focusing on buildings. Computer Vision and Image Understanding, 74(2): 138-149. 
Shufelt, J. A. and Mckeown, D. M., 1993: Fusion of Monocular Cues to Detect Man-Made Structures in Aerial Imagery. Image Understanding, 57(3): 307-330.

Zhang, K., Yan, J. and Chen, S.-C., 2006: Automatic construction of building footpoints from airborne LiDAR data. IEEE Transactions on Geoscience and Remote Sensing, 44(9): 2523-2533. https://doi.org/10.1109/TGRS.2006.874137

Müller, S. and Zaum, D. W. 2005: Robust bu1ldıng detection in aerial 1mages. In Proc. ISPRS Workshop CMRT ’05. Vienna.

Forlani, G., Nardinocchi, C., Scaioni, M. and Zingaretti, P. 2006: Complete classification of raw LIDAR data and 3D reconstruction of buildings. Pattern Analysis and Applications, 8(4): $357-374$.

Fradkin, M., Maître, H. and Roux, M., 2001: Building detection from multiple aerial 1mages in dense urban areas. Computer Vision and Image Understanding, 82(3): 181-207. https://doi.org/10.1006/CVIU.2001.0917

Awrangjeb, M., Zhang, C., \& Fraser, C. S., 2013: Automatic extraction of building roofs using LIDAR data and multispectral imagery. ISPRS Journal of Photogrammetry and Remote Sensing, 83: 1-18.

Vu, T. T., Yamazaki, F. and Matsuoka, M. 2009: Multi-scale solution for building extraction from LiDAR and image data. International Journal of Applied Earth Observation and Geoinformation, 11(4): 281-289.

Badenko V., Zotov D, Muromtseva N., Volkova Y., Chernov P, 2019: comparison of software for airborne laser scanning data processing in smart city applications. In Proc: ISPRS, Measurement, Visualisation and Processing in BIM for Design and Construction Management, Prague, Czech Republic

Meng, X., Currit, N. and Zhao, K., 2010: Ground filtering algorithms for airborne LiDAR data: A Review of critical issues. Remote Sensing, 2(12): 833-860.

Liu, X., 2008: Airborne LiDAR for DEM generation: some critical issues. Progress in Physical Geography, 32(1): 31-49. https://doi.org/10.1177/0309133308089496. 